\title{
MDD and BPD: Child maltreatment, stress, cortical thickness and volume
}

Vicente Camacho-Téllez1,2,3, M. S. Ladrón de Guevara1,2,3,5, A.E. Wainsztein11,2,3,5, X. Goldberg ${ }^{6}$, M. N. Castro1,2,3,5, C. García1,2,3 B.M. Duarte Abritta $^{1,2,3}$, C. Soriano-Mas ${ }^{7}$, N. Cardoner ${ }^{6}$, C. Nemeroff ${ }^{8}$, M.F. Villarreal1,2,3,4, S.M. Guinjoan $1,2,3,5$.

1Research Group on Neurosciences Applied to Behavioral Alterations. FLENI, Buenos Aires, Argentina. 2National Council of Scientific and Technological Research (CONICET), Argentina. 3Psychiatry Department. FLENI, Buenos Aires. 4Physics Department (FCEyN), Buenos Aires University, Argentina. 5Department of Psychiatry and Mental Health, Teaching Unit, FLENI, Buenos Aires University, School of Medicine, Argentina. 6Parc Taulí Universitary Hospital, Barcelona, España. 7Bellvitge Universitary Hospital (IDIBELL), Psychiatry, Barcelona, España. 8Texas University, Psychiatry, Austin, United States of America.

\section{Background and objective}

Adverse experiences in childhood have been related to structural and functional changes in the brain and in the neurobiological systems of stress $^{1}$; there is an association between suffering such experiences and developing mental illnesses in adulthood ${ }^{2}$ such as Major Depressive Disorder (MDD) or Borderline Personality Disorder (BPD) ${ }^{3}$.

Both disorders share clinical and biological characteristics, such as those related to the neural circuit that regulates emotions4; however, there is no consensus regarding whether they are two different manifestations of the same disease, or they are two independent entities 5 .

The objective is to describe the differences in cortical thickness, brain volumetry, the history of adverse childhood experiences between both disorders and explore the correlation between these experiences and cortical thickness.

\section{Methods}

\section{Participants}

\begin{tabular}{|c|c|c|c|}
\hline & CTRL (20) & MDD (19) & BPD (18) \\
\hline Gender & $5 \mathrm{M} ; 15 \mathrm{~W}$ & $5 \mathrm{M} ; 14 \mathrm{~W}$ & $8 \mathrm{M} ; 10 \mathrm{~W}$ \\
\hline Age & $\begin{array}{c}34.8 \pm \\
10.9 \text { years }\end{array}$ & $\begin{array}{c}48.6 \pm \\
14.0 \text { years }\end{array}$ & $\begin{array}{c}36.4 \pm \\
11.0 \text { years }\end{array}$ \\
\hline
\end{tabular}

\section{ACE-IQ6 \\ Adverse Childhood Experiences International Questionnaire}

Adverse Childhood Experiences (ACE) refer to some of the most intense and frequent sources of stress that children may suffer at an early age; include multiple types of abuse, negligence, violence between parents or caregivers, other types of serious domestic dysfunction, such as alcohol and substance abuse, and peer violence or violence in their community.

The ACE-IQ is intended to measure ACEs in people over 18 years of age. The greater the adversity in childhood, the higher the score and the greater the risk of subsequent health problems.
Magnetic

Resonance Images

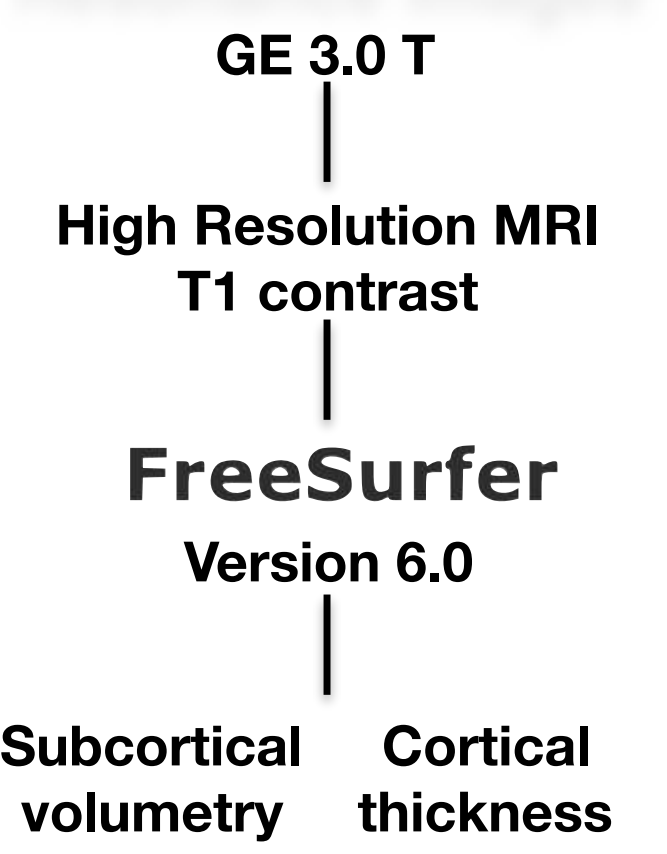

\section{Results and conclusions}

$$
\delta
$$

8
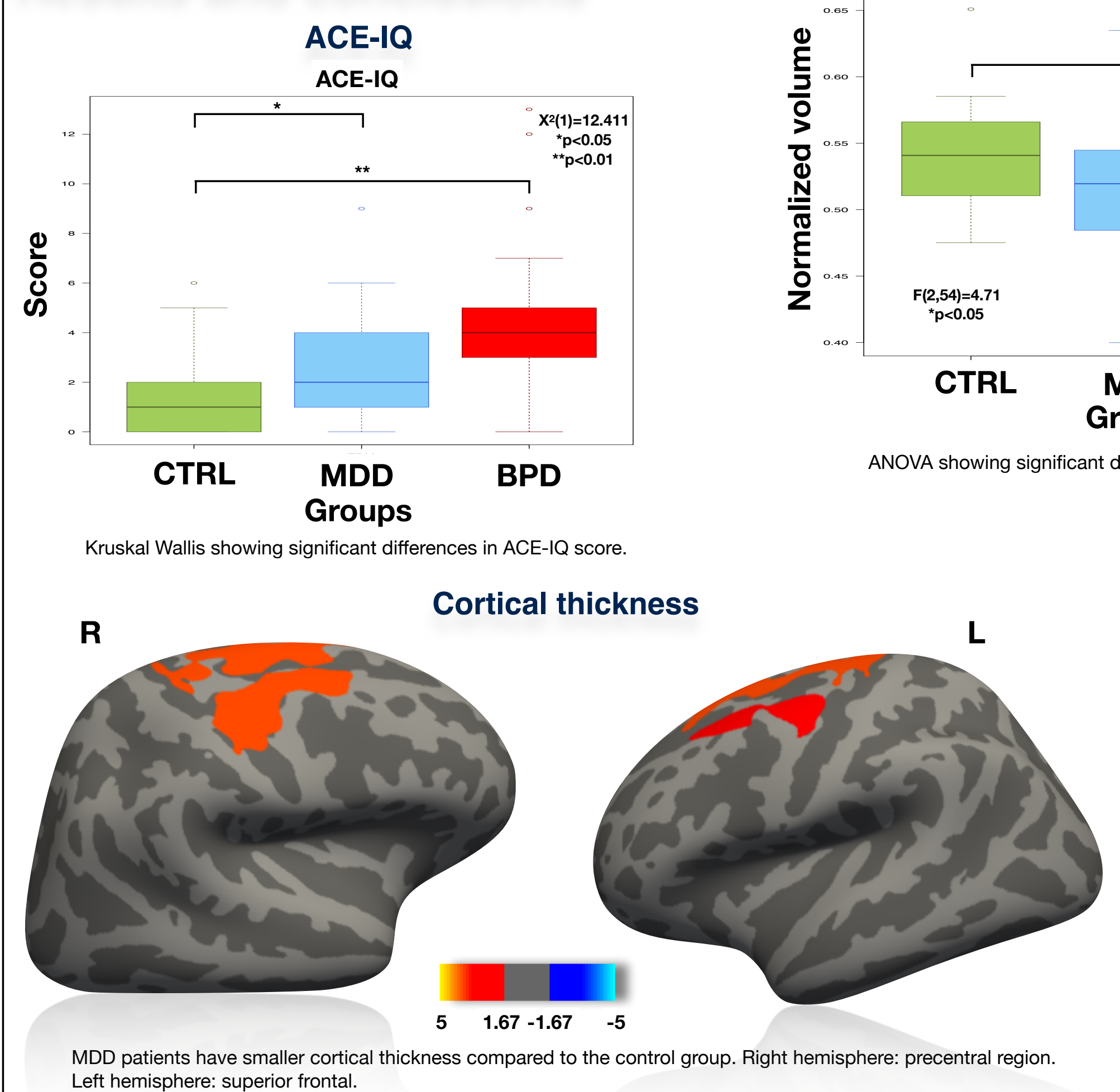
eft hemisphere: superior frontal.
Volumetry

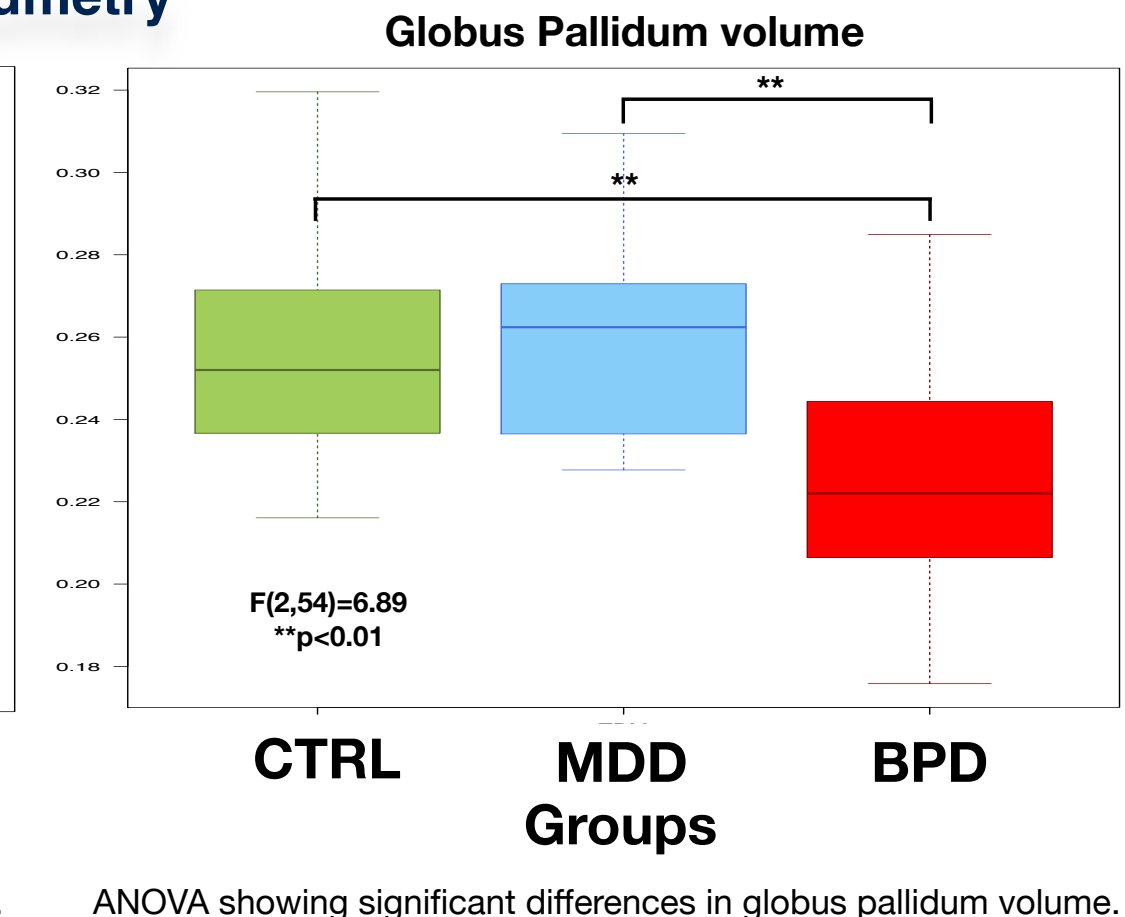

Correlation: Cortical thickness and ACE-IQ

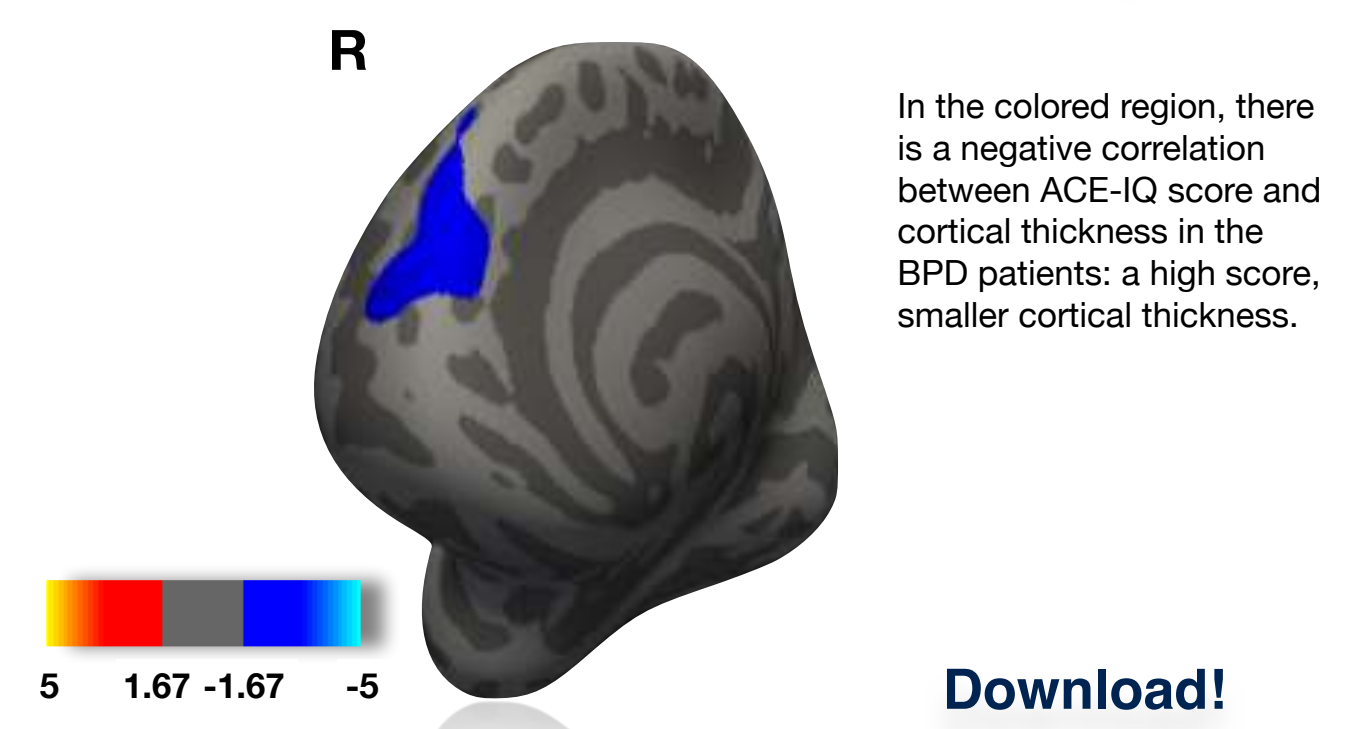

Download!

- The ACE-IQ score suggest the influence of ACE on the development of both disorders.

- The globus pallidum volume could be an indicator that differentiates both disorders.

- MDD patients have smaller cortical thickness.

- ACE could influence anatomical changes.

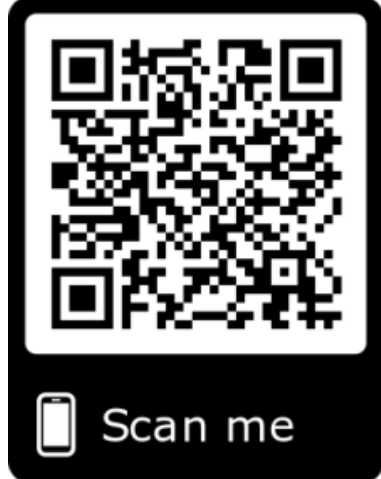

